\title{
The dynamical structure of intense Mediterranean cyclones
}

\author{
Emmanouil Flaounas · Shira Raveh-Rubin • \\ Heini Wernli $\cdot$ Philippe Drobinski $\cdot$ Sophie Bastin
}

Received: 24 December 2013 / Accepted: 9 September 2014 / Published online: 28 September 2014

(C) Springer-Verlag Berlin Heidelberg 2014

\begin{abstract}
This paper presents and analyzes the threedimensional dynamical structure of intense Mediterranean cyclones. The analysis is based on a composite approach of the 200 most intense cyclones during the period 19892008 that have been identified and tracked using the output of a coupled ocean-atmosphere regional simulation with $20 \mathrm{~km}$ horizontal grid spacing and 3-hourly output. It is shown that the most intense Mediterranean cyclones have a common baroclinic life cycle with a potential vorticity (PV) streamer associated with an upper-level cyclonic Rossby wave breaking, which precedes cyclogenesis in the region and triggers baroclinic instability. It is argued that this common baroclinic life cycle is due to the strongly horizontally sheared environment in the Mediterranean basin, on the poleward flank of the quasi-persistent subtropical jet. The composite life cycle of the cyclones is further analyzed considering the evolution of key atmospheric elements as potential temperature and PV, as well as the cyclones' thermodynamic profiles and rainfall. It is shown that most intense Mediterranean cyclones are associated with warm conveyor belts and dry air intrusions, similar to those of other strong extratropical cyclones, but of rather small scale. Before cyclones reach their mature stage, the
\end{abstract}

E. Flaounas $(\bowtie) \cdot S$. Raveh-Rubin $\cdot$ H. Wernli Institute for Atmospheric and Climate Science, ETH Zurich, Zurich, Switzerland

e-mail: flaounas@1md.polytechnique.fr

E. Flaounas $\cdot$ P. Drobinski

Institut Pierre Simon Laplace/Laboratoire de Météorologie

Dynamique, CNRS, Ecole Polytechnique, Palaiseau, France

S. Bastin

Université Versailles St-Quentin; Sorbonne Universités, UPMC

Univ. Paris 06; CNRS/INSU, LATMOS-IPSL, Guyancourt,

France streamer's role is crucial to advect moist and warm air towards the cyclones center. These dynamical characteristics, typical for very intense extratropical cyclones in the main storm track regions, are also valid for these Mediterranean cases that have features that are visually similar to tropical cyclones.

\section{Introduction}

The Mediterranean basin is one of the main cyclogenetic regions in the world (Ulbrich et al. 2009; Neu et al. 2013), where the most intense cyclones often produce high impact weather such as floods and windstorms (e.g., Jansa et al. 2000; Kotroni et al. 2006; Kysely and Picek 2007; Nissen et al. 2010; Pfahl and Wernli 2012). There is no objective classification of the strength or destructiveness of Mediterranean cyclones, however, it is commonly accepted that Medicanes and explosively intensifying cyclones constitute the most intense cases. Medicanes (merging of the words Mediterranean and Hurricanes; Emanuel 2005) are rare events of cyclones that present visual characteristics similar to tropical cyclones, such as an eye and a spiral of dense cloud coverage (Claud et al. 2010; Tous and Romero 2013). However, it appears that these systems have limited potential in reaching the wind speeds induced by a hurricane (Emanuel 2005). On the other hand, explosively deepening cyclones are systems that deepen rapidly within a short time, usually within about 12-24 h (e.g., Lagouvardos et al. 2007; Kouroutzoglou et al. 2011).

Tracking Mediterranean cyclones and identifying their physical properties is a challenge for cyclone tracking algorithms. This is mainly due to two reasons; first due to the fact that Mediterranean cyclones are highly variable in intensity, size and life time, and second due to the complex 
topography of the Mediterranean region with sharp transitions between the sea and mountainous land. Despite these difficulties, all studies analyzing cyclone tracks in the region agree that cyclogenesis is particularly frequent on the leeward side of the Alps and that the cyclones' sea level pressure (SLP) minima vary from relatively high values such as $1,030 \mathrm{hPa}$ to deep lows of the order of $980 \mathrm{hPa}$ (e.g., Trigo et al. 2002; Campins et al. 2011).

Previous studies have shown that intense Mediterranean cyclones develop within a baroclinic atmosphere and under the influence of prominent upper-tropospheric precursors. From observations and reanalyses it has been shown that these precursors mainly occur in the form of narrow potential vorticity (PV) streamers (Appenzeller and Davies 1992). Such PV streamers constitute a special form of short-wave upper-level troughs or positive upper-level PV anomalies, which were realized to be important for Mediterranean cyclogenesis already in the early studies by, e.g., Bleck and Mattocks (1984), Tosi et al. (1987) and Tafferner (1990). This importance of upper-level PV precursors is documented also in many recent studies (e.g., Homar et al. 2002; Chaboureau and Claud 2006; Nieto et al. 2008; Hanley and Caballero 2012; Tous and Romero 2013). Indeed, Fita et al. $(2006,2007)$ analyzed the contribution of several PV precursors to the development of strong Mediterranean cyclones and found that upper-level PV streamers play a dominant role. On the other hand, the authors showed that the diabatically generated PV at middle and lower atmospheric levels have a secondary impact on the cyclones' development. Similarly, local factors such orographic effects and air-sea interaction also play an important, but secondary, role for the evolution of Mediterranean cyclones (e.g., Campins et al. 2000; Trigo et al. 2002; Buzzi et al. 2003; Horvath et al. 2006; McTaggart-Cowan et al. 2010; Flaounas et al. 2013). Despite the fact that the majority of studies concentrated on Medicanes and explosive cyclones, an analysis of the three-dimensional structure of intense Mediterranean cyclones showed that they develop within a preceding upper-level trough (Campins et al. 2006).

Comparing Mediterranean cyclones with other extratropical cyclones, it appears that the former are typically of inferior intensity, life-time and size. Indeed, Campa and Wernli (2012) analyzed and compared the vertical PV structure of Mediterranean cyclones with other mature extratropical cyclones in the Northern Hemisphere for the period 1989-2009. They showed that on average intense Mediterranean cyclones are less deep (in terms of SLP) than intense cyclones in other regions and that they develop positive mid-tropospheric PV anomalies of only moderate intensity. The latter is true even for the deepest Mediterranean cyclones, suggesting that heating due to condensation of water vapor and the associated diabatic PV production are not the main driver for intense Mediterranean cyclones.
This result agrees with the analysis of previous case studies on tropical-like cyclones in the Mediterranean basin (e.g., Fita et al. 2007), but is in contrast to several cases of explosively deepening cyclones over the Atlantic (e.g., Stoelinga 1996; Wernli et al. 2002).

According to the current state-of-the-art in Mediterranean cyclone research, there are some major questions concerning the dynamical aspects of the most intense features. For instance, which environmental factors are favorable for Mediterranean cyclones to evolve into intense systems? Are there any dynamical criteria that separate Medicanes from the rest of the intense cases? Are Mediterranean cyclones a special case of extratropical cyclones? Especially for the latter it is highly interesting to investigate whether Mediterranean cyclones are also associated with warm conveyor belts (WCBs) and dry air intrusions (DAIs). These types of coherent airstreams are well known from studies of North Atlantic cyclones (e.g., Browning 1990; Wernli and Davies 1997) and WCBs have also been identified in idealized archetypal baroclinic wave life-cycles (Schemm et al. 2013; Schemm and Wernli 2014). Ziv et al. (2010) have specifically investigated these airstreams, and also cold conveyor belts (CCBs), for Mediterranean cyclones that occurred during the years 2002-2003. They performed an air parcel trajectory analysis for eight strong cyclones and with the use of subjective criteria they showed the existence of such airstreams also for Mediterranean cyclones. However, it is interesting that in a climatological study, Eckhardt et al. (2004) found no strong occurrence of winter WCBs over the Mediterranean region. This result contrasts with the regional frequency maximum of cyclogenesis in the Mediterranean in global cyclone tracking analyzes (e.g., Neu et al. 2013), suggesting that WCBs might not be a common feature among the tracked Mediterranean cyclones.

In this study, we apply a cyclone tracking approach in order to delineate the dynamical aspects of the life cycle of the 200 most intense Mediterranean cyclones, which occurred in a regional model simulation during a 20-year period (1989-2008). Our approach is to investigate composite fields, centered at the time and location of the cyclones' mature stage, making no distinction between Medicanes or other strong events. We follow the cyclones' dynamics, prior and after their maximum intensity, and we analyze important aspects of their baroclinic life cycle. For this reason we show the interaction of upper- tropospheric PV streamers with low-level temperature gradients, and we provide an insight on the development of the three-dimensional mesoscale dynamics that characterize the genesis and lysis of the cyclones. Furthermore we address the issue of different dynamical life cycles of intense Mediterranean cyclones and consequently examine the dynamical basis for distinguishing between Medicanes and other intense cyclones in the Mediterranean. Finally, we investigate the 


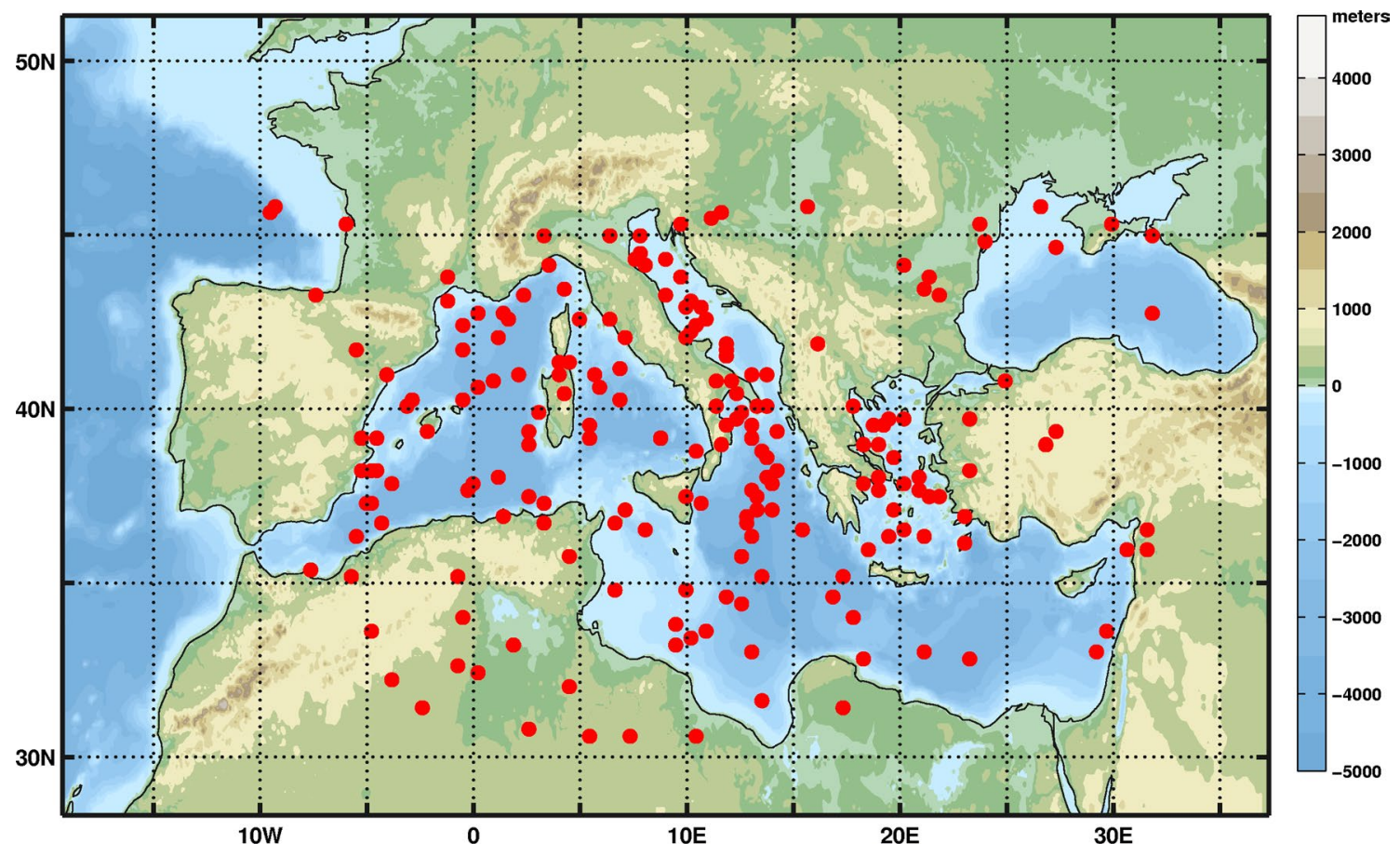

Fig. 1 The MORCE simulation domain and the terrain elevation and bathymetry. Red dots depict the 200 cyclone centers at the time of their maximum intensity

existence and structure of the WCB and DAI airstreams associated with Mediterranean cyclones and show their implication for the overall development of these systems.

Section 2 describes the methodology and datasets used in this study. Sections 3-5 present the results on the cyclones' dynamical evolution, their vertical structure, and the airstream analysis, respectively. Section 6 hosts the discussion of the results and Sect. 7 the conclusions and the prospects of this study.

\section{Models and methodology}

\subsection{Models}

In this study we use the results from a 20-year simulation (1989-2008) performed with the MORCE atmosphereocean coupling platform. The atmospheric component of MORCE is the Weather Research and Forecasting (WRF) model (Skamarock and Klemp 2008) and the oceanic component is the NEMO model (Madec 2008). Exchanges between the two components are performed every $3 \mathrm{~h}$, where WRF receives 3-hourly averaged sea surface temperatures (SST) and NEMO obtains 3-hourly averages of the 10-m wind stress and surface heat and radiation fluxes. More details on the set-up and functionalities of MORCE are given in Drobinski et al. (2012) and Lebeaupin-Brossier et al. (2013).
The WRF simulation domain, presented in Fig. 1, covers the Mediterranean region and is composed of $240 \times 130$ grid points with $20 \mathrm{~km}$ horizontal grid spacing and 28 terrain-following vertical levels. The domain is forced every $6 \mathrm{~h}$ at its lateral boundaries by ERA-Interim (ERA-I) reanalysis fields with $0.75^{\circ}$ horizontal resolution. Three-hourly model output is provided permitting a more detailed analysis of the cyclone tracks than with the standard 6-hourly outputs provided, e.g., by ERA-I. Grid nudging is applied over the whole domain, except within the boundary layer, for the fields of horizontal wind, temperature and water vapor. This simulation is performed in the context of the COordinated Regional Downscaling EXperiment (CORDEX, Giorgi et al. 2009) and its Mediterranean declination MED-CORDEX, and it contributes to the Hydrological cycle in Mediterranean Experiment (HyMeX, Drobinski et al. 2014) project, which aims to a better understanding of the Mediterranean water cycle.

In our simulation set-up, nudging is applied. Such technique consists of partially imposing the large scale of the driving fields on the regional climate simulation with the aim of disallowing large and unrealistic departures between driving and driven fields. In our article, the large-scale field is that of ERA-I reanalysis and the regional climate model is WRF. So during the simulation, WRF's prognostic variables are relaxed towards ERA-I field values within a predetermined relaxation time, here equal to $6 \mathrm{~h}$. Such value is the result of a trade-off between the adverse effect 
of nudging on small scales and the departure of the largescales from the ERA-I fields (Omrani et al. 2012, 2013). Nudging also ensures a dynamical consistency between the driving large-scale field and the simulated small-scale field permitting us also to take advantage of the added value of dynamical downscaling in analyzing the dynamics of Mediterranean cyclones at finer scales.

\subsection{Methodology}

Two types of input fields are commonly used for tracking cyclones: SLP, a field well describing the synoptic-scale structure of cyclones, and relative vorticity, a field that better captures the early phase of cyclones and smaller cyclones in general. In this article we performed tracking of Mediterranean cyclones based on the field of relative vorticity at the $850-\mathrm{hPa}$ level. Relative vorticity presents some advantages compared to SLP when used in a comparatively small and mountainous region as the Mediterranean. Indeed, relative vorticity is able to capture also small-scale circulation features, whereas SLP reflects mainly the synoptic-scale circulation and is subject to uncertainties due to below-ground extrapolation according to the hypsometric equation (especially over mountains). In addition, relative vorticity permits to track cyclones from their initial to their last vorticity signal, potentially before and after they present a closed SLP contour. This leads to longer tracks, potentially detecting cyclones earlier and therefore capturing a longer time until they reach their mature stage, which is an advantage when considering cyclones that reach this stage in a short time.

Cyclone tracking has been performed using the algorithm by Flaounas et al. (2014). In this study, a few changes have been made compared to the algorithm set-up in Flaounas et al. (2014), due to the high resolution of the input dataset and the specificity of Mediterranean cyclones. In summary, cyclone tracking is performed in two distinct steps: In step I, all cyclonic centers of the dataset are identified and located at each output time-step, for the whole period 1989-2008. Cyclone centers are defined as local maxima of relative vorticity within enclosed contours above a threshold value of $4 \times 10^{-5} \mathrm{~s}^{-1}\left(3 \times 10^{-5} \mathrm{~s}^{-1}\right.$ in Flaounas et al. 2014). Prior to the identification of cyclone centers, the raw relative vorticity fields were smoothed by applying three times a spatial moving average in an area of $10,000 \mathrm{~km}^{2}$ (i.e., $5 \times 5$ grid points). Tracking is then performed (step II) by connecting the identified cyclonic centers at consecutive time steps. This process is done by starting from the cyclonic center presenting the highest value of relative vorticity and then searching backward and forward in time for all possible tracks within a $5^{\circ} \times 5^{\circ}$ area $\left(10^{\circ} \times 5^{\circ}\right.$ in Flaounas et al. 2014). This process creates several candidate tracks associated with the same mature cyclonic state, i.e., the same track point of highest relative vorticity. The algorithm finally chooses the track that presents the least average difference of relative vorticity between consecutive track points, weighted by the distance between the track points. This algorithm differs from other tracking tools that have been used in the Mediterranean, especially when considering the tracking process (step II). Being a region with complex orography and sharp sea-land transitions, the Mediterranean region presents a large number of vorticity maxima and orographic pressure minima. As a result, when a tracking algorithm chooses the next location of a tracked feature there might be mistakes if many candidate cyclones are located close to each other. To avoid such mistakes our algorithm identifies all possible tracks and in step II it applies a low cost function based on physical criteria to determine the "correct" track.

In order to restrain our analysis to a statistically robust ensemble of intense Mediterranean cyclones, we take into account the 200 most intense cyclones of the 20-year period with a life time of at least 1 day (i.e., eight track points).The selected events are evenly distributed over the 20 years examined here and show no temporal trend. Hence we analyze about ten intense cyclones per year, a number consistent with previous studies on intense Mediterranean cyclones (e.g., Homar et al. 2007; Campa and Wernli 2012). Thirteen of the cyclones we detected were identified as Medicanes by the meteorology group of the University of Balearic Islands (www.uib.es/depart/dfs/meteorologia/ METEOROLOGIA/MEDICANES), among which figure the cases of September 2006 (e.g., Moscatello et al. 2008; Chaboureau et al. 2012) and January 1995 (Pytharoulis et al. 2000; Emanuel 2005). Both cases have recently attracted a lot of scientific attention.

\section{The cyclones' dynamical evolution}

Figure 1 presents the location of the centers of the identified most intense cyclones at the time of maximum relative vorticity, while Fig. 2 presents the seasonal cycle of occurrence and the distribution of the maximum intensity of the 200 cyclones. All detected cyclones are mainly distributed over the central and western Mediterranean, with some "hot spots" over the Adriatic Sea (Fig. 1). The seasonal cycle of the most intense 200 events is shown in Fig. 2a, presenting a minimum of occurrence during summer and a maximum in winter. This seasonal cycle of cyclone occurrences comes in accordance with the results of Flaounas et al. (2013) who detected all Mediterranean intense cyclones for the same period as here but using ERA-I. The latter implies that with respect to the seasonal cycle there is no timing preference for the development of intense cyclones in the region. Concerning the 200 cyclones' maximum intensity histogram, 
Fig. 2 a Monthly distribution of the 200 intense cyclones. b Histogram of the 200 cyclones' maximum intensity in terms of relative vorticity
(A) Cyclogenesis Seasonal Cycle

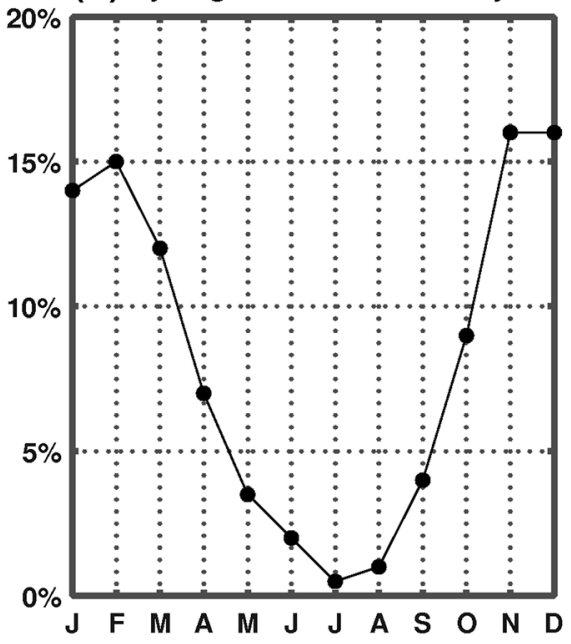

(B) Histogramme - Relative Vorticity

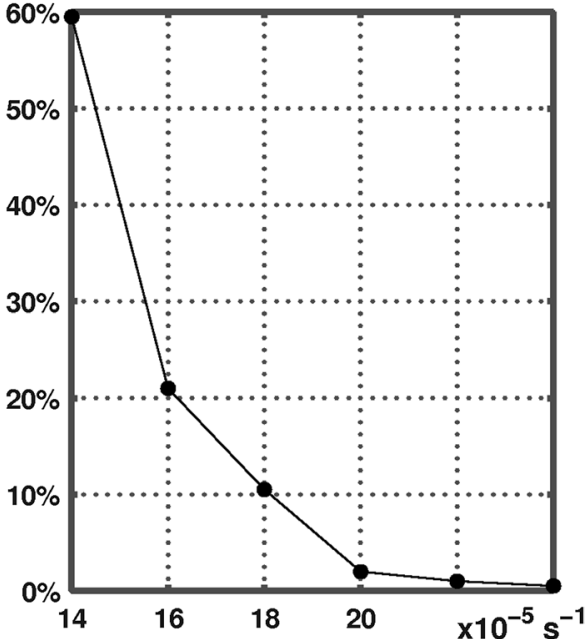

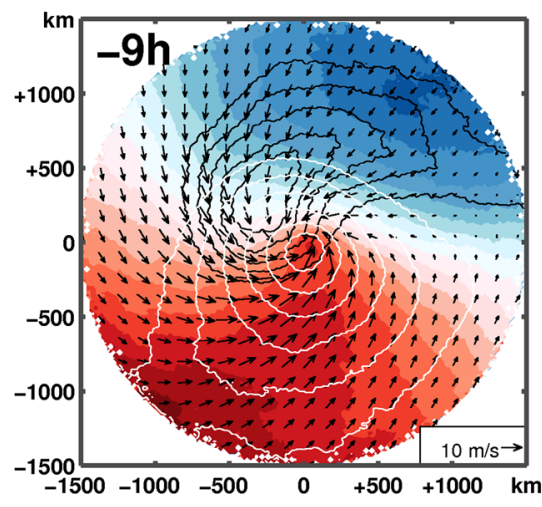

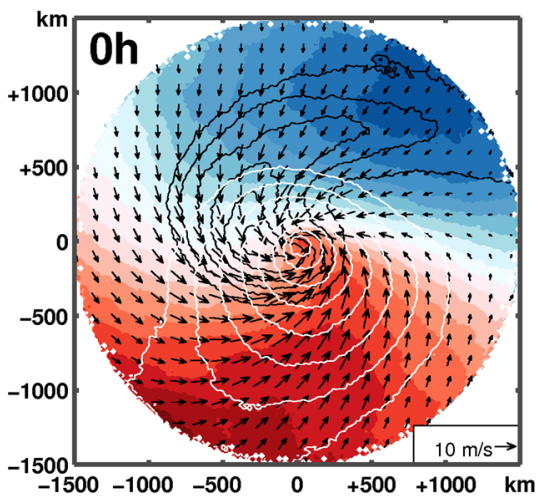

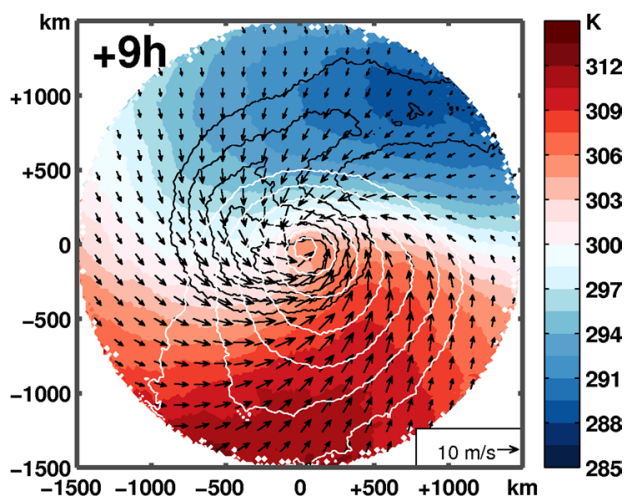

Fig. 3 Composites for all 200 cyclones of equivalent potential temperature at $850 \mathrm{hPa}$ (in colors), horizontal wind vectors at $850 \mathrm{hPa}$ (arrows), sea level pressure (white contours, every $2 \mathrm{hPa}$ with
1,014 hPa being the outermost contour) and the pressure of the 2-PVU tropopause (black contours, every $15 \mathrm{hPa}$ starting at $290 \mathrm{hPa}$ ) at the times $-9,0$ and $+9 \mathrm{~h}$
Fig. $2 b$ shows a sharp decrease for approximately $95 \%$ of the cases, revealing that the strongest cyclones (with peak relative vorticity of more than $20 \times 10^{-5} \mathrm{~s}^{-1}$ ) account for about $5 \%$ of all cases. The minimum SLP of all 200 cases ranged between 975 and $1,015 \mathrm{hPa}$, while about $30 \%$ of the cases presented values of around $1,000 \mathrm{hPa}$ (not shown).

To gain an insight in the dynamical evolution of the 200 intense cyclones, composites of atmospheric fields are constructed within circular areas with a radius of $1,500 \mathrm{~km}$, spatially centered at the cyclone track points and temporally centered at the time of their maximum relative vorticity. We follow a similar approach as in Catto et al. (2010) and we perform a rotation of all fields. For this reason, we first select an example case. Here we use the Medicane occurring on 15/12/2005 over the Mediterranean Sea close to the African coast (Fita et al 2007) as this example case due to its well-defined eastward track and cold and warm fronts. The fields for the remaining 199 cyclones were rotated for all angles between $0^{\circ}$ and $350^{\circ}$, with an interval of $10^{\circ}$. The finally chosen rotation angle for each cyclone is the one that leads to the largest spatial correlation of 850$\mathrm{hPa}$ equivalent potential temperature between the example Medicane and the cyclone under consideration. The purpose of rotating all cyclones is for their composite to present a frontal structure that is as coherent as possible. Most cyclones were rotated by no more than $20^{\circ}-30^{\circ}$. Our analysis was also performed without rotating the cyclone fields, which did not significantly affect the results. Hereafter, all composites are calculated with fields that were previously rotated.

Figure 3 shows the composite fields of equivalent potential temperature $\left(\theta_{\mathrm{e}}\right)$ and wind at $850 \mathrm{hPa}$, SLP and tropopause pressure, where the dynamical tropopause is defined here as the 2 PVU surface. The fields are shown at the times $-9 \mathrm{~h}(9 \mathrm{~h}$ before the cyclones reach their mature 
state), $0 \mathrm{~h}$ (mature stage with maximum relative vorticity) and $+9 \mathrm{~h}(9 \mathrm{~h}$ after reaching their mature stage). Figure 3 reveals that during this $18 \mathrm{~h}$ time period the dynamical tropopause tends to wrap cyclonically around the cyclone center, reflecting a PV streamer, which gradually intrudes deeper into the troposphere. In parallel, $\theta_{\mathrm{e}}$ gradients become stronger, behind and ahead of the cyclone, forming a weak cold front and a more pronounced warm front. During the mature state of the cyclones, the PV streamer intrudes deepest over the cold front, the $850-\mathrm{hPa}$ winds reach their maximum magnitude and the fronts are fairly perpendicular to each other near the center. At $+9 \mathrm{~h}$, the cold and warm fronts are displaced towards the east and the PV streamer is located directly above the cyclone center. It is very important to note the fact that well-defined structures occur in the cyclone composites indicates that the 200 cases have a similar structure and that the resulting fields are dynamically meaningful. This cannot be taken for granted a priori, since very large variability could in principal lead to strongly smoothed composite fields, which would not reveal interesting information.

In order to better understand the dynamical aspects of the composite cyclone life cycle we follow the methodology of Campa and Wernli (2012) by averaging several key fields for the development of extratropical cyclones within a radius of $200 \mathrm{~km}$ around the cyclone center. The $200 \mathrm{~km}$ radius is also consistent with the characteristic radius of Medicanes as diagnosed by Tous and Romero (2013). The temporal evolution of these fields along the cyclone tracks provides a compact means to quantify important changes during the life cycle. As a result, Fig. 4 shows time series of spatially averaged potential temperature $(\theta)$ and relative vorticity at $850 \mathrm{hPa}$, middle tropospheric PV (vertically averaged between 850 and $500 \mathrm{hPa}$ ), and tropopause pressure. To ease comparison between fields of different units and magnitudes, all time series are normalized with respect to their average (averages and standard deviations are shown in Fig. 4). Relative vorticity at $850 \mathrm{hPa}$ evolves symmetrically before and after the time of maximum intensity $(0 \mathrm{~h})$. During cyclone intensification (from -9 to $0 \mathrm{~h}$ ), relative vorticity at $850 \mathrm{hPa}$ is well correlated with vertically averaged PV in the middle troposphere. This is expected since the diabatic PV production necessarily also leads to an increase of relative vorticity. Both time series reach their maximum at $0 \mathrm{~h}$. Thereafter, the middle tropospheric PV decays slower than low-level relative vorticity. One possible explanation for this is that diabatic PV production is continuing after time $0 \mathrm{~h}$ with reduced amplitude and with a shift of the production maximum to slightly higher levels. This would be reflected in a faster decrease of relative vorticity at $850 \mathrm{hPa}$. The tropopause pressure and $\theta$ at $850 \mathrm{hPa}$ evolve with an opposing influence on cyclone intensification. Indeed, low-level

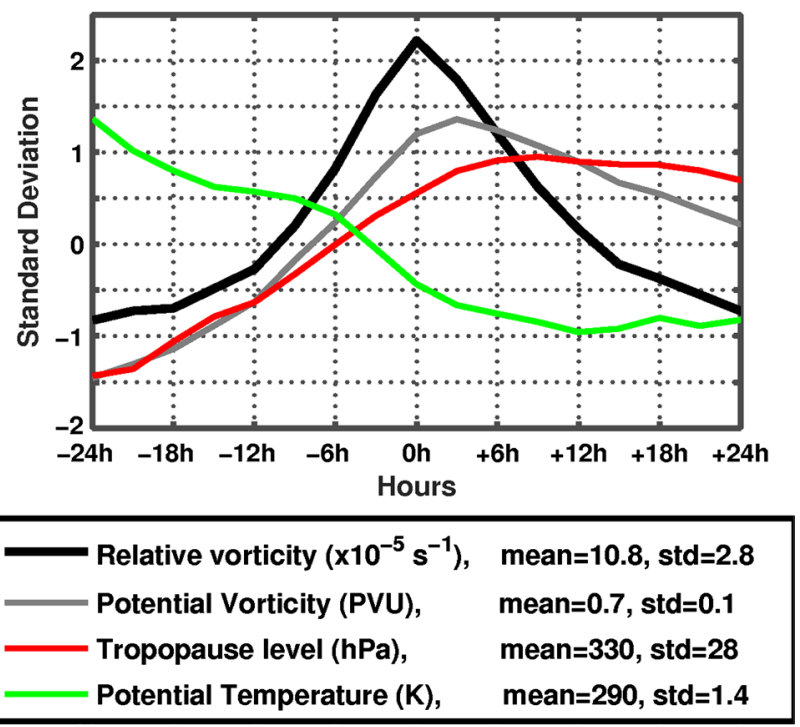

Fig. 4 Composite time series of atmospheric fields, averaged in a $200 \mathrm{~km}$ radius around the track points of all 200 cyclone tracks, centered in time such that $0 \mathrm{~h}$ corresponds to the track point with maximum relative vorticity. The presented fields are the $850 \mathrm{hPa}$ relative vorticity and potential temperature, mid-tropospheric PV (averaged between 850 and $500 \mathrm{hPa}$ ), and pressure of the 2-PVU tropopause. To ease comparison, all fields are normalized and displayed in units of standard deviations

$\theta$ values decrease as the PV streamer wraps around the cyclone center, whereas at the same time tropopause pressure increases as the PV streamer intrudes deeper into the troposphere. This co-evolution is valid until approximately $0 \mathrm{~h}$, when the tropopause pressure reaches its maximum and $\theta$ at $850 \mathrm{hPa}$ its minimum value. This is also evident in Fig. 3, where it is shown that cold temperatures prevail in the cyclone center at $0 \mathrm{~h}$, while the PV streamer is located very close to the cyclone center.

A principal component analysis has been applied for all time series used in Fig. 4 in order to determine if the averaged evolution of $\theta$, middle atmosphere PV and tropopause pressure level presented in Fig. 4 is representative for the baroclinic life cycle of the 200 cases. The results yield a similar evolution of the three variables for all cases, regardless of their location, season or intensity (not shown). In summary, the cyclones' mature stage occurs in phase with the formation of a so-called PV tower over the cyclone center, i.e., a vertical structure with anomalously high PV values throughout the troposphere. This occurs just before the PV streamer wraps over the cyclone center and the surface fronts dislocate to the east of the cyclone center. Then, the surface cyclone intensity decreases as the cyclone center is located in the cold air, diabatic processes that produce the mid-tropospheric PV anomaly get weaker, and the PV streamer remains located above the cyclone center without further intruding. 

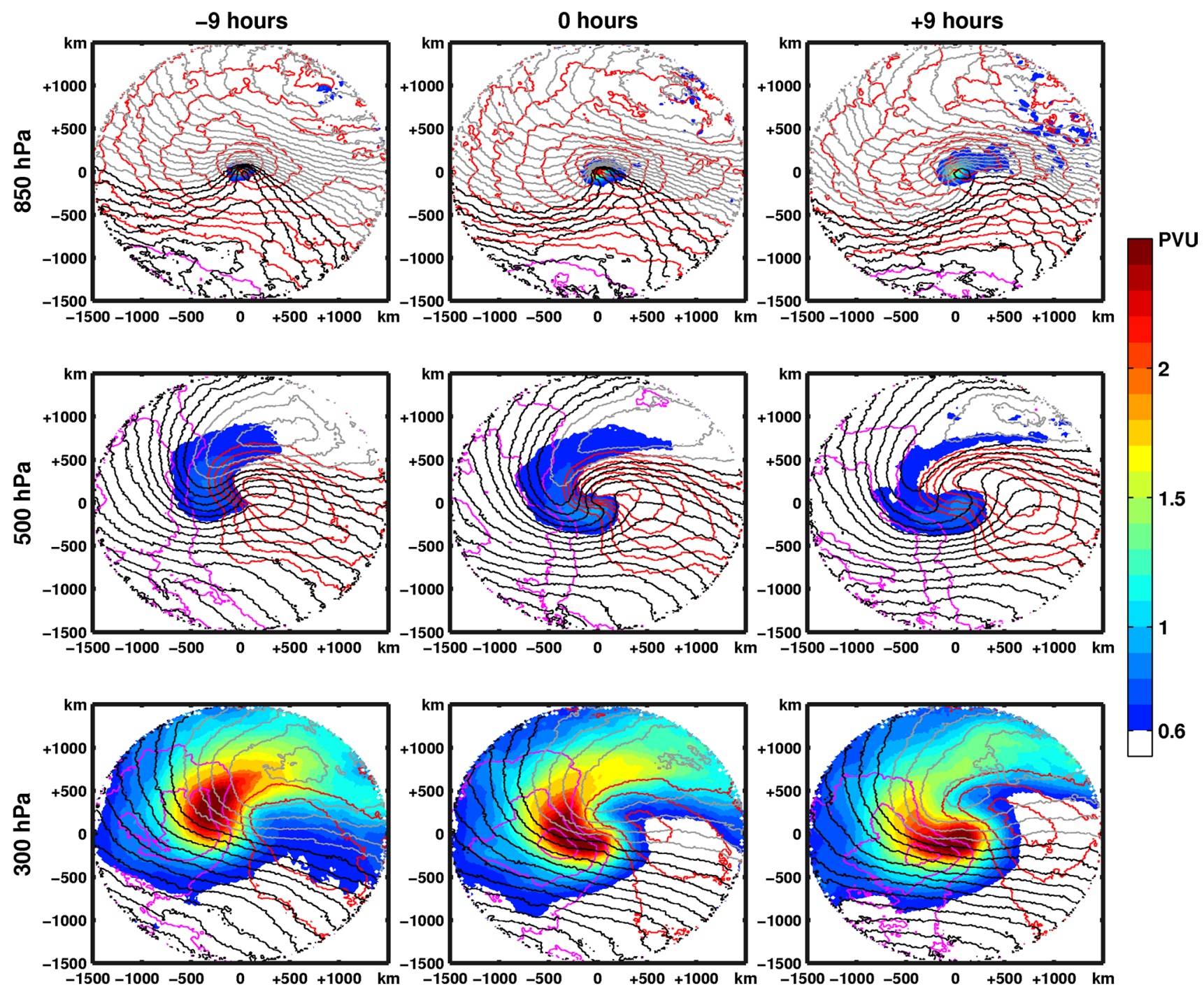

Fig. 5 Composites for all 200 cyclones, at the times $-9,0$ and $+9 \mathrm{~h}$ of potential vorticity (in color), equivalent potential temperature (black and gray contours) and relative humidity (red and magenta contours) at 850, 500 and $300 \mathrm{hPa}$. The equivalent potential tem-

To gain further insight into the cyclones three-dimensional structure, Fig. 5 shows the fields of $\theta_{\mathrm{e}}$ and $\mathrm{PV}$ at the levels of 850,500 and $300 \mathrm{hPa}$ at the times $-9,0$ and $+9 \mathrm{~h}$. At all three times, the cyclonic PV streamer is evident at $300 \mathrm{hPa}$, characterized by high PV values, while it is also visible at $500 \mathrm{hPa}$ but with weaker PV values $(<2$ PVU), suggesting that the tropopause unlikely reaches such low pressure levels. At $850 \mathrm{hPa}$, the highest $\mathrm{PV}$ values are always located over the cyclone center, reaching their maximum (more than $2 \mathrm{PVU}$ ) at $0 \mathrm{~h}$, in accordance with the relative vorticity evolution (Fig. 4). In agreement with the composite PV profiles shown by Campa and Wernli (2012), $\mathrm{PV}$ values are always weaker at $500 \mathrm{hPa}$ than at $850 \mathrm{hPa}$, suggesting that diabatic PV production is most pronounced at low atmospheric levels during the cyclone intensification. perature contour interval is $1 \mathrm{~K}$, while the gray contours mark values below $305 \mathrm{~K}$ at 850 and $500 \mathrm{hPa}$ and below $315 \mathrm{~K}$ at $300 \mathrm{hPa}$. Relative humidity red contours start at $50 \%$ and have an interval of $5 \%$, magenta contours start at $40 \%$ and decrease by an interval of $5 \%$

From Fig. 5 it is evident that there are two main positive $\mathrm{PV}$ anomalies. One at $850 \mathrm{hPa}$ over the cyclone center and another one at $300 \mathrm{hPa}$ that is further upstream and in the form of a PV streamer. Not surprisingly, the westward tilt between the lower and upper anomalies is stronger at time $-9 \mathrm{~h}$, when the PV streamer is located further to the northwest of the cyclone center, and weaker at $+9 \mathrm{~h}$, when the PV streamer is above the cyclone center. In a conceptual two-layer model (see, e.g., Figure 18 in Hoskins et al. 1985), the concentrated high PV values at $850 \mathrm{hPa}$ above the cyclones center results in a cyclonic circulation around the center. On the other hand, the peak in the equatorward wind at $300 \mathrm{hPa}$ induced by the lower levels is, due to the tilted PV structure, right at the location of the streamer, which further intensifies the upper-level anomaly. Similarly, 

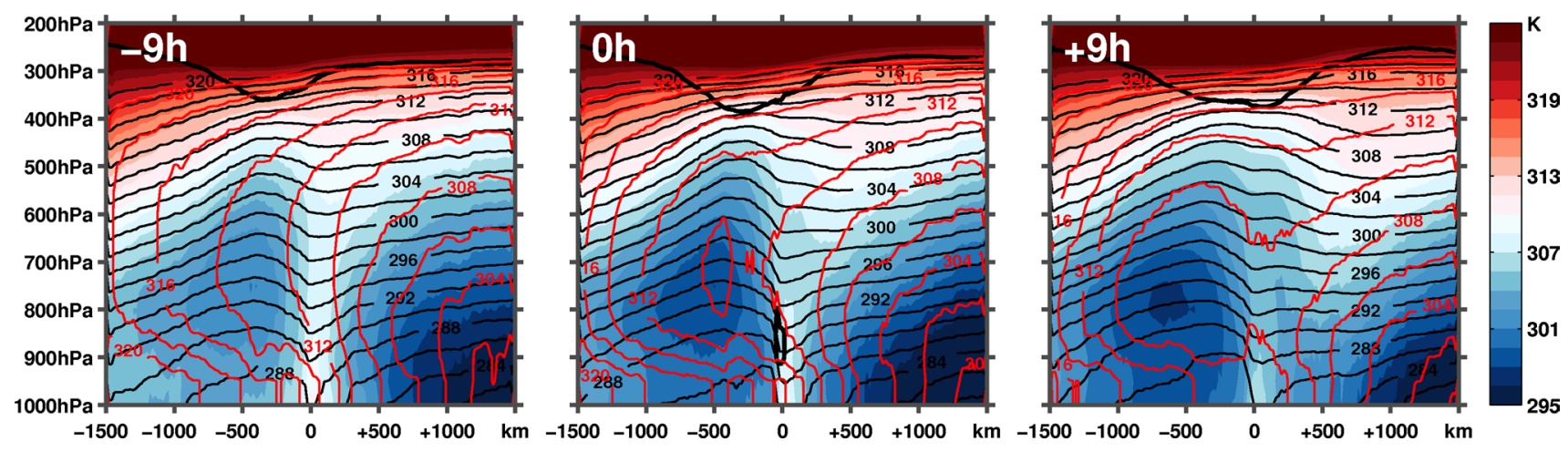

Fig. 6 Vertical cross-section composites for all 200 cyclones at the times $-9,0$ and $+9 \mathrm{~h}$. The sections extend zonally from $-1,500$ to $+1,500 \mathrm{~km}$ across the cyclone center, which is located at the horizontal coordinate 0 . The fields shown are equivalent potential temperature (in color), the 2-PVU surface (black thick contour), poten-

this tilted configuration favors advection of warm $\theta_{\mathrm{e}}$ values from the south and towards the cyclone center induced by the displaced upper-level PV streamer. What is remarkable is that we find these classical patterns of baroclinic interaction when considering the composite structure of the most intense Mediterranean cyclones simulated at fairly high resolution.

As the PV streamer approaches the cyclone center, the reduction of tilting reinforces the low level rotational circulation around the cyclone center. The warm sector is displaced eastwards, since the low-level warm air advection is also displaced in-phase with the upper-level PV streamer. The eastward in-phase displacement between the warm sector and the PV streamer is shown clearly by comparing the $305 \mathrm{~K}$ contour of $\theta_{\mathrm{e}}$ at $850 \mathrm{hPa}$ with the location of the PV streamer at $300 \mathrm{hPa}$. These findings agree with the analysis of a North Atlantic cyclone by Davis and Emanuel (1991), who performed a piecewise PV inversion of the upper and lower PV anomalies to show the resulting surface $\theta$ fields in a similarly "PV-tilted environment". Although in their case study the stronger PV anomaly was detected at the surface, the upper-level PV anomalies contributed significantly to advect warm $\theta$ values towards the cyclone center due to the imposed wind field at lower levels prior and during the maximum intensity of the cyclone (see their Fig. 9a, b).

\section{Vertical structure, thermodynamic profiles and rainfall}

Figure 5 shows relative humidity at 850,500 , and $300 \mathrm{hPa}$. While at $850 \mathrm{hPa}$ the higher values $(>70 \%)$ are always concentrated close to the cyclone center (times -9 , 0 and $+9 \mathrm{~h}$ ), at 500 and $300 \mathrm{hPa}$ the spatial structure of tial temperature (black contours) and the saturation equivalent potential temperature (red contours). Notice except from the upper troposphere, the 2-PVU surface is also visible at the cylone center, at $850 \mathrm{hPa}$, at $0 \mathrm{~h}$

humidity is more asymmetric due to the approach of the PV streamer. Moist values occur typically on the eastern side of the cyclone and over the surface warm front. Dry values $(<40 \%)$ are clearly located at 500 and $300 \mathrm{hPa}$ to the western side of the cyclone and over the cold front. The low values of relative humidity at the western side of the cyclones and within the middle and upper troposphere suggest that dry air parcels are advected from the northwest in parallel with the PV streamer wrapping around the cyclone center. This issue is analyzed further in the next section.

To better understand the thermodynamic evolution near the cyclone center, Fig. 6 shows vertical sections from west to east across the cyclone center of the fields $\theta \mathrm{e}, \theta$, saturation equivalent potential temperature $\left(\theta \mathrm{e}^{*}\right)$, and the 2 PVU isosurface at times $-9,0$ and $+9 \mathrm{~h}$. The three variables $\theta, \theta \mathrm{e}$ and $\theta \mathrm{e}^{*}$ provide a comprehensive description of the thermodynamic profile of the atmosphere. Indeed, during the motion of an air parcel its $\theta$ and PV values are both conserved under adiabatic conditions, while its $\theta \mathrm{e}$ value is conserved even if condensation occurs. In fact, $\theta \mathrm{e}$ expresses the $\theta$ value of a parcel, after it was heated by condensation of all its moisture content and its negative vertical gradient expresses a potentially unstable atmospheric layer. Hence, Fig. 6 provides an insight on the dynamical relation between $\theta$ and $\mathrm{PV}$, while $\theta \mathrm{e}$ provides an insight on the moist thermodynamic frontal structure of the cyclones. On the other hand, $\theta \mathrm{e}^{*}$ refers to the atmospheric state and does not constitute an air mass tracer (Holton 2004). The values of $\theta \mathrm{e}^{*}$ are the equivalent of $\theta \mathrm{e}$, but for a supposed saturated atmosphere, where a negative vertical gradient of $\theta \mathrm{e}^{*}$ reveals an area of conditional instability (Holton 2004). Consequently, differences between $\theta$ and $\theta$ e reflect the resulting temperature difference due to condensational heating, while differences between $\theta \mathrm{e}$ and $\theta \mathrm{e}^{*}$ are proportional to the ratio between the actual temperature and the 
temperature needed for a saturated atmosphere. By definition, all $\theta, \theta \mathrm{e}$ and $\theta \mathrm{e}^{*}$ are equal to each other in the absence of moisture.

From a dynamical perspective, Fig. 6 shows again the evolution of the PV streamer: at $-9 \mathrm{~h}$ it is located approximately at $-300 \mathrm{~km}$, i.e., to the west of the cyclone center, then at $0 \mathrm{~h}$, the streamer reaches deeper pressure levels (approximately $400 \mathrm{hPa}$ ), and finally at $+9 \mathrm{~h}$ it is displaced over the cyclone center, while its penetration in the troposphere becomes zonally wider. It is noteworthy that at $0 \mathrm{~h}, \mathrm{PV}$ values larger than $2 \mathrm{PVU}$ are observed over the cyclone center at $850 \mathrm{hPa}$ (see caption of Fig. 6) reflecting the maximum cyclone intensity in terms of relative vorticity increased by the intense diabatic PV production within the lower troposphere. The $\theta$ surfaces slope upward at $-500 \mathrm{~km}$, west of the cyclone center, to reach their lowest pressure beneath the PV streamer and downslope sharply over the cyclone center. This reflects the sharp transition between the cold air to the west of the cyclone center and the warm sector to the east.

At all three times presented in Fig. 6, Oe shows two distinct cold regions, one to the west of the cyclone center and an even more pronounced one to the east of the cyclone center where the $\theta \mathrm{e}$ values are below $300 \mathrm{~K}$ in the lowest $200 \mathrm{hPa}$, indicating that the cyclones move towards colder regions. The differences between $\theta$ and $\theta \mathrm{e}$ are smaller over the west side of the cyclone center and beneath the PV streamer (at $-500 \mathrm{~km}$ ). This reflects less water content and agrees with Fig. 5, which shows relative humidity values below $50 \%$ at 500 and $300 \mathrm{hPa}$. The dry air to the west of the cyclone center is consistent with the spatial pattern of DAIs, descending behind the cold front (shown in the following section).

East of the cyclone center, the $\theta \mathrm{e}$ contours intersect vertically the $\theta$ isosurfaces by sloping sharply from the cyclone center upwards and towards the east. The differences between $\theta \mathrm{e}$ and $\theta$ are large, representing the potential heat release of the atmospheric water content due to condensation. This upward slope of the $\theta \mathrm{e}$ contours from the lower to the mid levels represents the warm front structure. Indeed, the low-level moist air parcels which move northeastwards from the cyclone warm sector (see wind field in Fig. 3), will upslope the front, following the iso- $\theta$ e surfaces and probably form the WCBs. Consequently, upward moving air masses over the warm front tend to moist the middle troposphere as shown by the high relative humidity values in Fig. 5 at $500 \mathrm{hPa}$ at all times. In summary, the two regions east and west of the cyclone center present a thermodynamic structure that is strongly modulated by water vapor. Indeed, the western side of the cyclone center is characterized by dry air due to DAIs and due to advection from the north by the PV streamer, while the eastern side is characterized by warm and moist air coming from the south, upsloping the warm front and moistening the middle and upper troposphere.

In the cyclone center, at $-9 \mathrm{~h}$ there are high values of $\theta \mathrm{e}$ above the center which extend through the entire troposphere and separate the two cold regions. However, at 0 and $+9 \mathrm{~h}$ the transfer of air with low $\theta \mathrm{e}$ from the northwest of the cyclone (alongside the PV streamer) fills the cyclone center with colder $\theta \mathrm{e}(<310 \mathrm{~K})$. This goes along with the displacement of the warm sector to the east (Figs. 3, 5 at $+9 \mathrm{~h}$, at $850 \mathrm{hPa}$ ). It is also interesting to note that at times -9 and $0 \mathrm{~h}$ the cyclone center is characterized by a low-level temperature maximum, sometimes referred to as warm air seclusion (e.g., Neiman and Shapiro 1993). From a PV perspective, the vertical alignment of a positive PV anomaly in the upper troposphere (indicated by the low tropopause), the diabatically produced positive PV anomaly at $850 \mathrm{hPa}$, and the surface warm anomaly at $0 \mathrm{~h}$ constitute an ideal configuration for intense cyclones (e.g., Davis and Emanuel 1991; Campa and Wernli 2012). Nine hours later at $+9 \mathrm{~h}$, the warm air seclusion and the low-level PV weaken, in agreement with the slow decay of the cyclone intensity (Fig. 4). The two distinct regions separated by the warmer center were also observed in composite vertical profiles of Atlantic extratropical cyclones (Catto et al 2010).

Due to the moisture content difference between the regions west and east of the cyclone center, the high $\theta \mathrm{e}^{*}$ values tend to extend zonally from the east to the west. Indeed, comparing the same pressure levels, the dry air in the west results in higher $\theta \mathrm{e}^{*}$ values than in the east. Consequently, the westward zonal extension of high values of $\theta \mathrm{e}^{*}$ provokes a negative vertical gradient of the field near the cyclone center and within the middle troposphere (between 800 and $500 \mathrm{hPa}$ ). This atmospheric layer above the cyclone center is conditionally unstable, suggesting that stronger convective rainfall is likely to take place over the cyclone center. Indeed, the accumulated rainfall patterns are in agreement with the areas of conditional instability. Figure 7 shows the total 6-hourly accumulated rainfall at $-9,0$ and $+9 \mathrm{~h}$. It is interesting that at -9 and $0 \mathrm{~h}$ the strongest rainfall is observed close to the cyclone center, slightly displaced to the northeast (Fig. 7), while at $+9 \mathrm{~h}$ the rainfall pattern attains a more comma-like shape, indicative of intense precipitation along the warm front. Also at $+9 \mathrm{~h}$, the conditional instability is slightly reduced.

Compared to the environment, the peak precipitation values in the cyclone center at -9 and $0 \mathrm{~h}$ are enhanced by almost one order of magnitude. The link of this rainfall pattern to the existence of airstreams is discussed in the next section. A strong, potentially convective, peak close to the surface cyclone center has been previously observed in composite studies of extratropical cyclones, using satellite observations, reanalyses and models (e.g., Chang and 


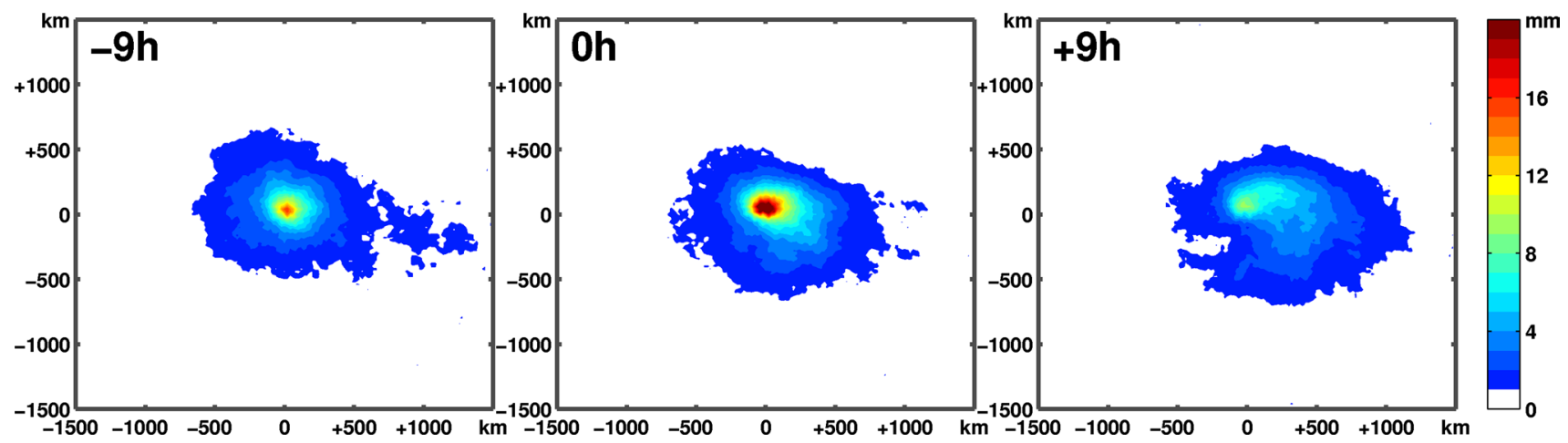

Fig. 7 Composites of the horizontal distribution of 6-hourly accumulated precipitation for all 200 cyclones, at the times $-9,0$ and +9 h. The coordinate $(0,0)$ indicates the cyclone center

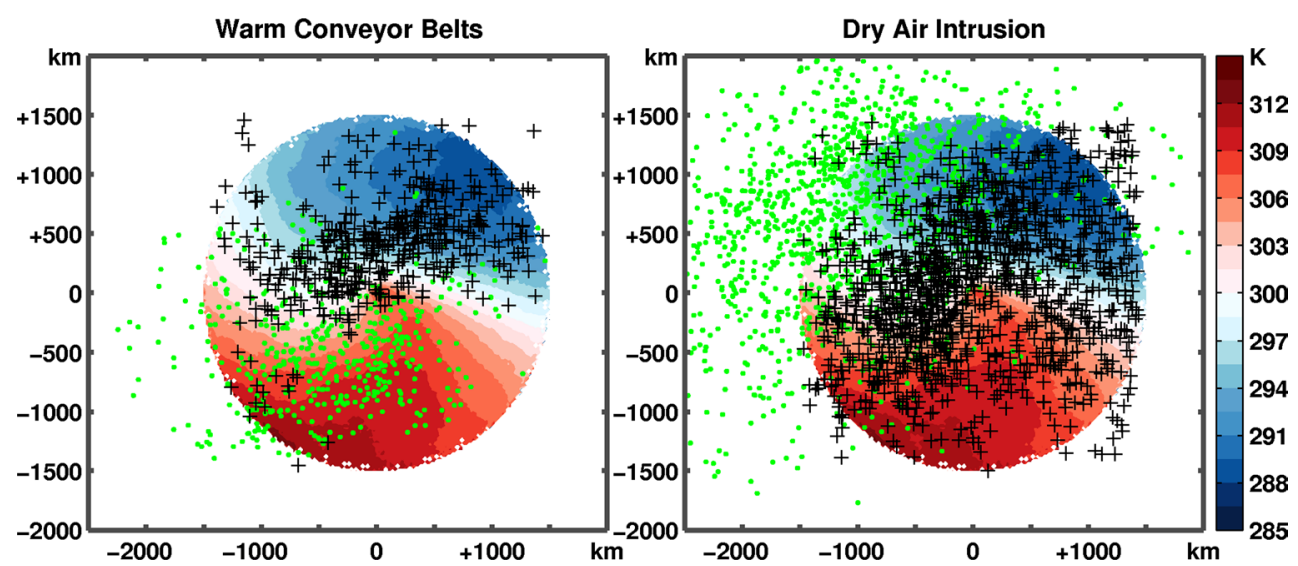

Fig. 8 Composites of equivalent potential temperature at $850 \mathrm{hPa}$ for all 200 cyclones (in color) at the time of maximum cyclone intensity ( $0 \mathrm{~h}$ ). Green dots correspond to the position of airstreams at $-24 \mathrm{~h}$ (WCBs and DAIs), while black crosses correspond to their position at $0 \mathrm{~h}$

Fig. 9 Time series of the median (middle line), and the 10th and 90th percentiles (upper and bottom line) of potential vorticity, pressure level, mixing ratio along, $\theta$ and $\theta \mathrm{e}(\theta \mathrm{e}$ is in dashed line) for all detected WCBs of the 200 cyclones. The percentiles are calculated separately at each time
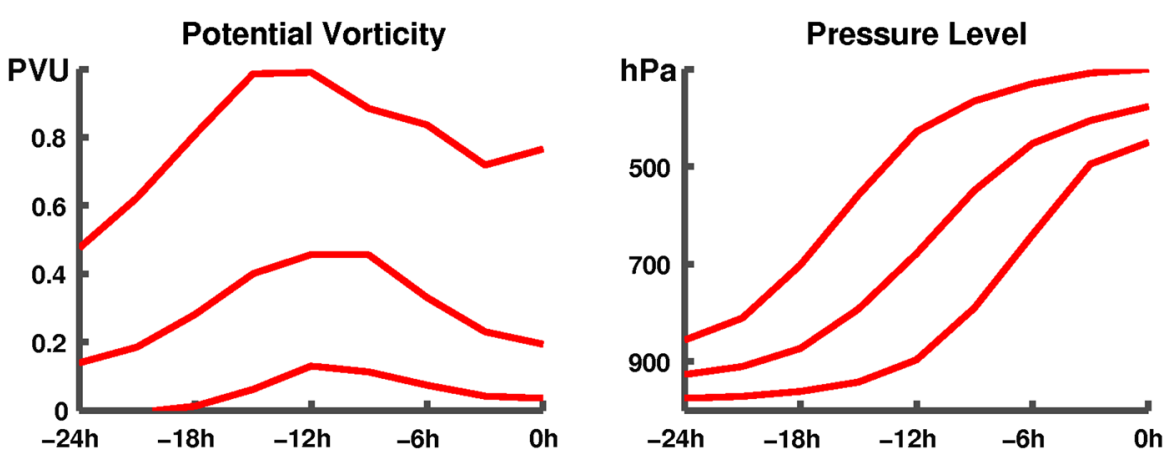

Mixing Ratio

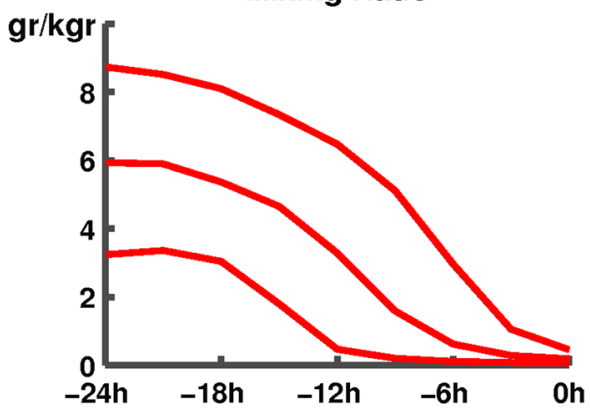

$\theta \mathbf{e} \& \theta$

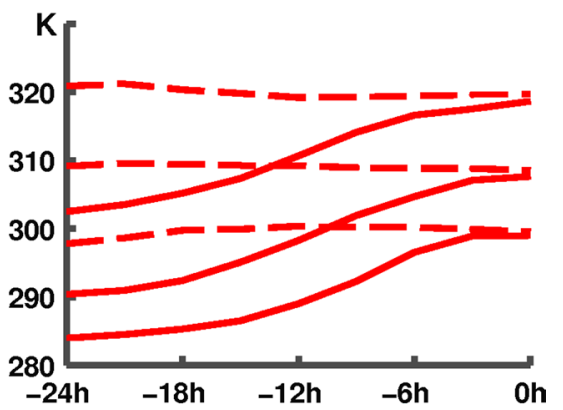


Song 2006; Field et al. 2011). In particular, Field and Wood (2007) considered rainfall composits for different categories of extratropical cyclones, depending on their wind strength and moisture content. According to their results (their Fig. 8) it is only the weak cyclones and those of moderate intensity that present a pronounced rainfall peak close to the cyclone center and less rainfall over the warm front, similarly to our rainfall pattern at 0 and $+9 \mathrm{~h}$ in Fig. 7. The fact that the spatial rainfall pattern of our stronger Mediterranean cyclones is similar to the patterns shown for weak to moderate extratropical cyclones in the main storm track areas is consistent with the fact that even the most intense Mediterranean cyclones are shown to be comparatively weak compared to the other cyclones forming over the main oceans (e.g., Campa and Wernli 2012).

\section{Warm conveyor belts and dry air intrusions}

From a Lagrangian viewpoint, one of the most prominent features of extratropical cyclones is the existence of coherent airstreams, i.e., of WCBs and DAIs. As outlined in the introduction, WCBs have been identified as air parcels with a strong ascent from the boundary layer to the upper troposphere (forming the often comma-shaped cloud pattern at the warm front). In contrast, DAIs are dry air parcels, typically originating from the stratosphere, that descend behind the cold front and forming a cloudless region (e.g., Browning 1997). These two airstreams are the most fundamental ones when considering baroclinic instability, as they provide a large fraction of the involved poleward transport of warm air and equatorward transport of cold air (e.g., Thorncroft et al. 1993); and they are therefore investigated in this study. Starting at $0 \mathrm{~h}$ for each of the 200 cases, 24-h backward trajectories were initiated on a regular grid, separated by $40 \mathrm{~km}$ in the horizontal and $50 \mathrm{hPa}$ in the vertical between 1,000 and $200 \mathrm{hPa}$, using the Read/Interpolate/ Plot utility (RIP; see http://www.mmm.ucar.edu/wrf/users/ docs/ripug.htm). WCBs were identified as trajectories that ascended at least $500 \mathrm{hPa}$, while DAIs were identified as trajectories with average relative humidity of $<30 \%$ and of average PV of more than 2 PVU. Note that this criterion for DAIs selects airstreams that remain entirely in the stratosphere and airstreams that cross the 2-PVU tropopause (as long as the averaged values exceed 2 PVU).

Numerous trajectories met the WCB and DAI criteria and indeed, both airstreams could be identified for almost all cyclones. In order to provide an insight to the spatial organization of these airstreams, we performed a trajectory clustering analysis, separately for WCBs and DAIs, based upon the trajectories' three-dimensional positions, following the method introduced by Moody et al. (1998). First, all longitudes, latitudes and pressure coordinates of the trajectories have been normalized with respect to the cyclone center. Then, a square matrix $\mathrm{D}_{\mathrm{ij}}$ has been constructed, where each element represents the average normalized distance between the $\mathrm{i}$-th and $\mathrm{j}$-th trajectories. Finally, a cluster includes all trajectories that do not vary by more than two standard deviations of the normalized average distance. Figure 8 shows the location of all WCB and DAI clusters at -24 and $0 \mathrm{~h}$, together with the $850 \mathrm{hPa}$ $\theta_{\mathrm{e}}$ distribution of the Mediterranean cyclone composite at the time of the backward trajectory initialization (i.e., at $0 \mathrm{~h}$ when the cyclones attain their maximum relative vorticity at $850 \mathrm{hPa}$ ). In order to gain further insight to the physical characteristics of the WCBs, Fig. 9 shows for all trajectory clusters the median, and the 10th and 90th percentiles of $\mathrm{PV}$, relative vorticity, mixing ratio, $\theta \mathrm{e}$ and $\theta$ as a function of time.

Figure 8 shows that WCBs start their ascent at $-24 \mathrm{~h}$ from the warm sector, while their outflow at $0 \mathrm{~h}$ is close to the tropopause, located mainly over regions with cold $\theta_{\mathrm{e}}$ at $850 \mathrm{hPa}$ to the north of the cyclone center. This pattern is partially consistent with WCBs in other extratropical cyclones. Indeed, in the Mediterranean WCBs present an equally strong rise of air parcels from lower to upper levels, transferring air masses with low PV (in average $<1 \mathrm{PVU}$ ) to the upper troposphere (Fig. 9, left top panel). On the other hand, a specific aspect of Mediterranean WCBs is that they start fairly close to the cyclones and hence over the Sea (see green dots in Fig. 8), since the basin is surrounded by land which is also particularly dry over Northern Africa. This is different compared to cyclones over the main storm track regions, where WCBs can originate far equatorward from the cyclone center and travel over long meridional distances. Indeed, Madonna et al. (2014) showed that on average WCBs start ascending with a mixing ratio of $\sim 10 \mathrm{~g} /$ $\mathrm{kg}$, compared to $6 \mathrm{~g} / \mathrm{kg}$ found in the Mediterranean (Fig. 9, bottom left panel, at $-24 \mathrm{~h}$ ). It is also important to note that the Mediterranean is not a particular WCB "hot-spot" (Eckhardt et al. 2004; Madonna et al. 2014) although the cyclone frequency is high. The results of this study therefore indicate that the most intense Mediterranean cyclones indeed have WCBs, whereas weaker cyclones in the same region are devoid of such strongly ascending airstreams. In summary, the Mediterranean WCBs start within the warm sector (Fig. 8) and they ascend rapidly (Fig. 9, top right panel) close to the cyclone center and over the warm front. This ascent of WCBs close to the cyclone potentially contribute to the torrential rain pattern in Fig. 7 (at $-9 \mathrm{~h}$ and at $0 \mathrm{~h}$ ) as their air masses lose their water content (Fig. 9, bottom left panel) and present latent heating which raises the median $\theta$ values by about $20 \mathrm{~K}$ (Fig. 9, bottom right panel). This is consistent with Pfahl et al. (2014), who showed that WCBs contribute to $20-60 \%$ of the extreme precipitation events in the Mediterranean, depending on the region. The 
$\theta_{\mathrm{e}}$ values (dashed line in bottom right panel of Fig. 9) are fairly well conserved even when condensation occurs. The range of $\theta_{\mathrm{e}}$ values from 300 to $320 \mathrm{~K}$, as shown in Fig. 9, is consistent with the $\theta_{\mathrm{e}}$ values of the warm sector in Fig. 8.

Figure 8 shows that all DAI trajectories start to the northwest or west of the cyclones and arrive at $0 \mathrm{~h}$ behind the cold front, in accordance with the conceptual picture of airstreams during the development of baroclinic waves (e.g., Browning 1997). Some of the DAIs originate southwest of the cyclone center, from the dry continental areas of North Africa. The detected DAIs descend on average by $100-200 \mathrm{hPa}$ in $24 \mathrm{~h}$ and they are equally distributed in the mid and upper troposphere. The DAIs have averaged PV values of 2-7 PVU and mixing ratios inferior than $1 \mathrm{~g} /$ $\mathrm{kg}$. During the descent, these values slight decrease for PV and increase for water vapor, most likely due to mixing with ambient moister air. The role of DAIs for the (thermo) dynamics of extratropical cyclones is unclear. As discussed in Browning (1997), they might enhance conditional instability and the advection of high PV values might enhance the cyclonic circulation. In our 200 cases we did not find a significant correlation between the intensity of DAIs and the cyclones.

In summary, we performed an extended analysis of WCBs and DAIs on a large population of intense Mediterranean cyclones, by applying objective criteria for their identification. Our results are consistent with $\mathrm{Ziv}$ et al. (2010), who analyzed WCB and DAI trajectories for eight cases of intense Mediterranean cyclones. In their analysis, the WCBs extended $<2,000 \mathrm{~km}$ to the south of the cyclone center and they originated in most cases over the Sahara. In our case the WCBs were found to originate from the sea and close to the cyclone, however our trajectories are relatively short $(24 \mathrm{~h})$ and it is possible that some of them come from further south. However, even if the WCBs are traced to originate from arid North Africa, their main source of water vapor is the Mediterranean Sea through surface evaporation. This geographical setting and the moisture uptake fairly close to the cyclone center is a specificity of WCBs associated with Mediterranean cyclones.

\section{Discussion}

\subsection{On the Mediterranean cyclones common baroclinic life-cycle}

Different baroclinic life cycles have been produced previously in idealized baroclinic wave experiments, emphasizing the importance of the atmospheric barotropic shear for the development of the upper-level flow structures (e.g., Davies et al. 1991; Thorncroft et al. 1993). Thorncroft et al. (1993) presented two archetypal paradigms of baroclinic life cycles with strikingly different types of upper-level PV streamers. In situations with cyclonic barotropic shear in the ambient mean state, the simulated PV streamer presented a "cyclonic" life cycle which is very similar to the one identified in this study for the Mediterranean cyclones. In their simulation, this cyclonic wrapping up of the PV streamer occurred on the cyclonic (poleward) side of the jet. Later, Shapiro et al. (1999) suggested that in the real atmosphere, the cyclonic barotropic shear in the region of the polar jet might be an effect of the presence of a strong subtropical jet. Indeed, for some cases of intense Mediterranean cyclones it was shown that the polar and the subtropical jets interact with the surface cyclone on its northern and southern side, respectively (Prezerakos et al. 2006). It is noteworthy that we found no atmospheric mid-level PV production or rainfall along the cold front. This suggests that frontal precipitation (and thus PV production through diabatic heating) does not occur as a robust feature for all cases. This is consistent with the weak cold front typically generated during the development of the "cyclonic life cycle" as proposed by Thorncroft et al. (1993). Certainly it wouldn't be surprising if we got cold frontal convective rainfall in some cases, however, they would be a minority and consequently their signal would be weak in the composite.

Using again our ensemble approach, Fig. 10 presents the composites for all 200 cyclones of wind speed and direction at $300 \mathrm{hPa}$, and SLP at $0 \mathrm{~h}$. Here ERA-I data have been used, in order to cover a larger region that extends over the entire North Atlantic (i.e., beyond the WRF domain). All fields have been centered at the location of the cyclones given by maximum relative vorticity, as shown in Fig. 1. The coordinates in Fig. 10 are hence relative to the cyclone centers and expressed in degrees. The Mediterranean basin is zonally located approximately within $-20^{\circ}$ to $+20^{\circ}$ and meriodionally between $-15^{\circ}$ and $+15^{\circ}$. Strong winds are associated with the polar jet at $+15^{\circ}$ relative latitude, extending zonally from $-100^{\circ}$ to $+20^{\circ}$, and the subtropical jet at $-20^{\circ}$ relative latitude (i.e., about 2,000 km equatorward of the surface cyclone). It is thus very likely that the subtropical jet exerts a large impact on the baroclinic development in the Mediterranean by providing strong cyclonic shear, which provokes the cyclonic life cycle of the upper-level PV pattern associated with the Mediterranean cyclone as proposed by the earlier studies.

\subsection{On the intensity of Mediterranean cyclones}

In the previous sections we showed that the most intense Mediterranean cyclones present characteristics that are well known from studies of cyclones in the main storm 
Fig. 10 The composite wind field (arrows) and wind speed (colors) at $300 \mathrm{hPa}$, and SLP (black contours) for all 200 cyclones at time $0 \mathrm{~h}$ and centered relative to the position of the cyclone center $\left(\right.$ at $\left.0^{\circ} / 0^{\circ}\right)$. Fields are taken from ERAInterim reanalyses

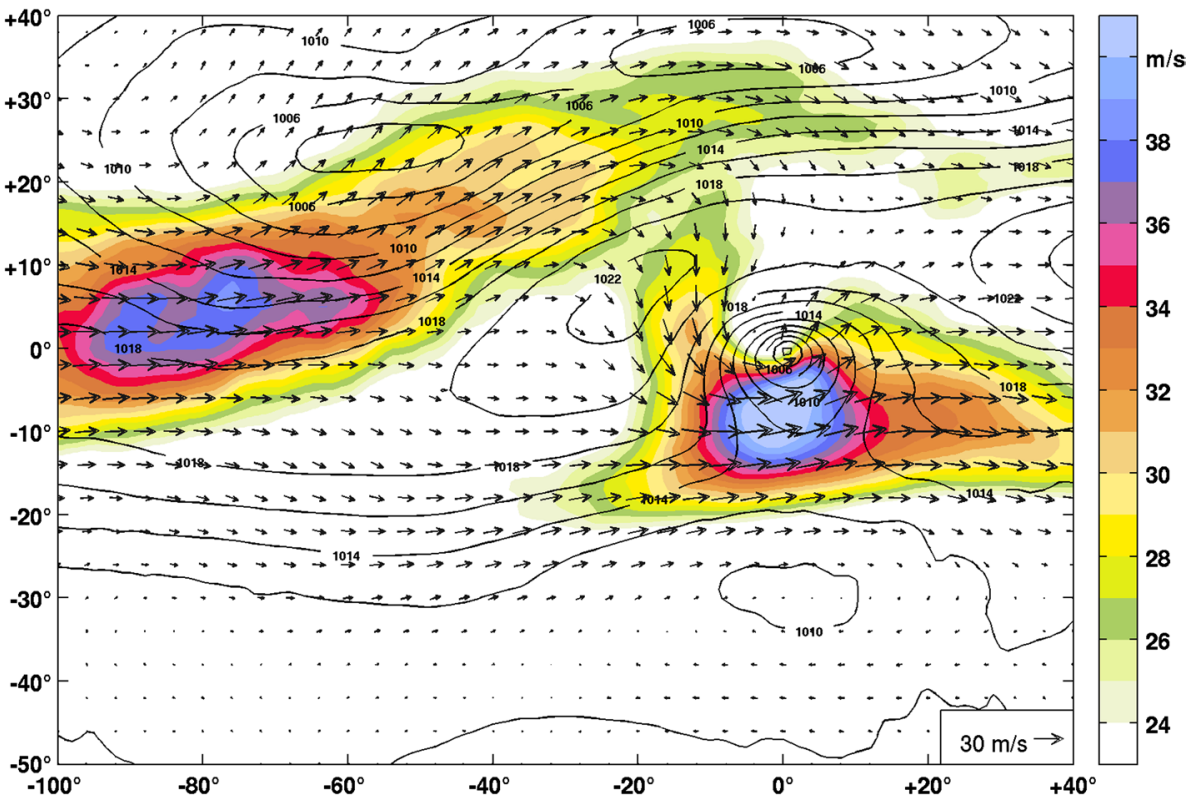

weaker cyclones. The weaker category is composed of the consecutive 200 most intense cyclones. For reasons of consistency we only take into account cases that present their maximum intensity over the Mediterranean Sea. This is necessary to avoid effects from orographic PV generation, such as orographic PV banners (e.g., Schär et al. 2003), and to assure similar geographic conditions. This forms a set of 141 out of the 200 most intense cyclones and 129 out of the 200 weaker cyclones.

Figure 11 shows the differences of the vertical PV profiles at $-9,0$ and $+9 \mathrm{~h}$ between the most intense and the weaker cases, averaged within a $200 \mathrm{~km}$ radius around the cyclone center. At $0 \mathrm{~h}$, i.e., at the time of maximum cyclone intensity, the more intense cyclones have higher PV values in the lower troposphere. Interestingly, at $300 \mathrm{hPa}$, the PV differences are first negative (at $-9 \mathrm{~h}$ ), then they get reduced (at $0 \mathrm{~h}$ ), and finally they turn positive at $+9 \mathrm{~h}$ (+0.2 PVU). This change of sign is due to two facts: (1) the PV streamer has lower PV values for the weaker cases and (2) the PV streamer reaches the center of the intense cyclones later than for the weaker cases. Indeed, at $-9 \mathrm{~h}$ the PV streamer of the weaker cases covers more of the area defined by the $200 \mathrm{~km}$ radius around the cyclone center, leading to a higher PV average in the upper troposphere. Later, when the PV streamers wrap around cyclone center (from 0 to $+9 \mathrm{~h}$ ), they fill the $200 \mathrm{~km}$ radius around the cyclones and the PV difference becomes positive due to the higher PV values of the streamer for the most intense cases.

As discussed in Sect. 3, the shift between the surface cyclone center and the upper-tropospheric streamer is important for the formation of the Mediterranean cyclones. Indeed, before reaching the cyclone center, the PV streamer clinic dynamics controlling the intensity of Mediterrane cyclones we compare our most intense cases with a set of 
imposes a cyclonic circulation in the lower troposphere, which advects warm and moist air towards the cyclone center, similarly to the cyclogenesis scenario by Hoskins et al. (1985). Consequently it comes as no surprise that at $-9 \mathrm{~h}$ the weaker cases present lower values of $\theta_{\mathrm{e}}$ in the lower troposphere (between 1,000 and $500 \mathrm{hPa}$ ) compared to the most intense cases. Following the same analysis

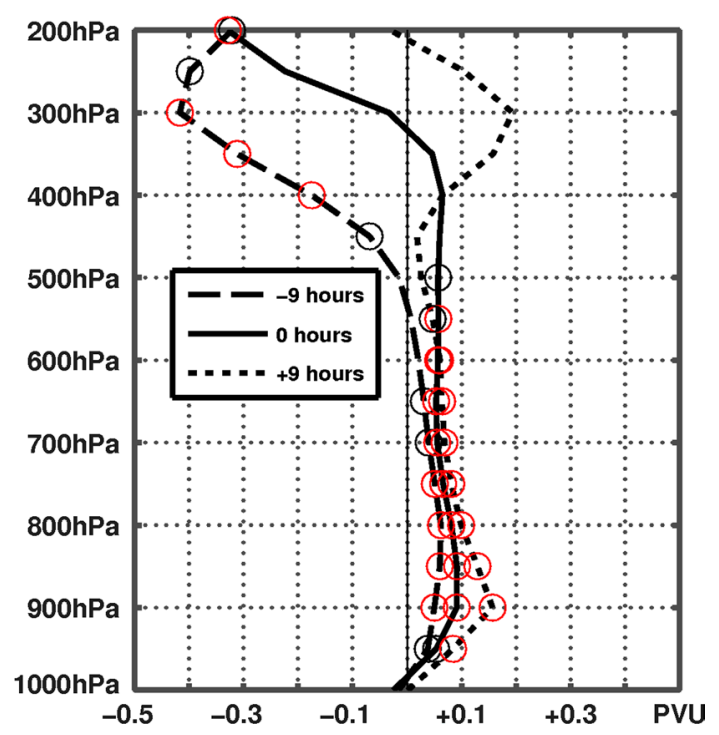

Fig. 11 Vertical profiles of the PV difference averaged in a radius of $200 \mathrm{~km}$ around the cyclone center between 141 more intense and 129 weaker events, at $-9 \mathrm{~h}$ (dashed line), $0 \mathrm{~h}$ (solid line), and $+9 \mathrm{~h}$ (dotted line). For each pressure level, the circles denote the $5 \%$ (red circles) and $20 \%$ (black circles) level of significance of the difference between the averages of the two cyclone groups. Significance is determined by a two-samples $t$ test, examining the rejection of the null hypothesis that the profiles of the two cyclone groups, separately at each level, come from independent random samples of normal distributions with equal means as for Fig. 11, the $\theta_{\mathrm{e}}$ differences between the intense and weaker cases are constantly of the order of $+0.5 \mathrm{~K}$ between 1,000 and $700 \mathrm{hPa}$, revealing more moisture (i.e., more moist static energy) for the most intense cyclones. This difference in moist static energy suggests that ascending air masses from the center of the intense cyclones would reach the lifting condensation level earlier for similar profiles of $\theta_{\mathrm{e}}{ }^{*}$. Indeed, average 6-hourly accumulated rainfall at $0 \mathrm{~h}$ within the radius of $200 \mathrm{~km}$ around the cyclone center of the most intense cases is on average $9 \mathrm{~mm}$, compared to approximately $3 \mathrm{~mm}$ for the weaker cases. More rainfall for the most intense cases is consistent with the +0.1 PVU difference at $850 \mathrm{hPa}$ in Fig. 11.

To extend our analysis, Fig. 12 shows for all 200 intense cases and the following 200 weaker cases identified in Sect. 6.2 , the scatterplot of PV at $850 \mathrm{hPa}$ versus $\mathrm{PV}$ at $300 \mathrm{hPa}$, both averaged within $200 \mathrm{~km}$ around the cyclone center at $-9,0$ and $+9 \mathrm{~h}$. It is noteworthy that at $0 \mathrm{~h}$ about 20 cyclones out of the 200 most intense cases present $300-\mathrm{hPa}$ PV values smaller than 1 PVU. Further analysis on these cases showed that they present a cyclonic PV streamer and a baroclinic life cycle similar to the other intense cases as discussed above. However, their PV streamer is slightly further to the west of the cyclone center and less deeply penetrating into the troposphere. We also distinguish a total of 13 Medicanes in our dataset of the 200 most intense cyclones, as identified and documented by the meteorology group of the University of Balearic Islands (Tous and Romero 2013). Interestingly, Fig. 12 shows that Medicanes always have high values of low-level PV compared to the majority of the cyclones, even at $-9 \mathrm{~h}$, when relative vorticity has not reached its maximum value at $850 \mathrm{hPa}$. On the other hand, Medicanes tend to have rather low PV values at $300 \mathrm{hPa}$, also at $+9 \mathrm{~h}$ when the PV streamer is located
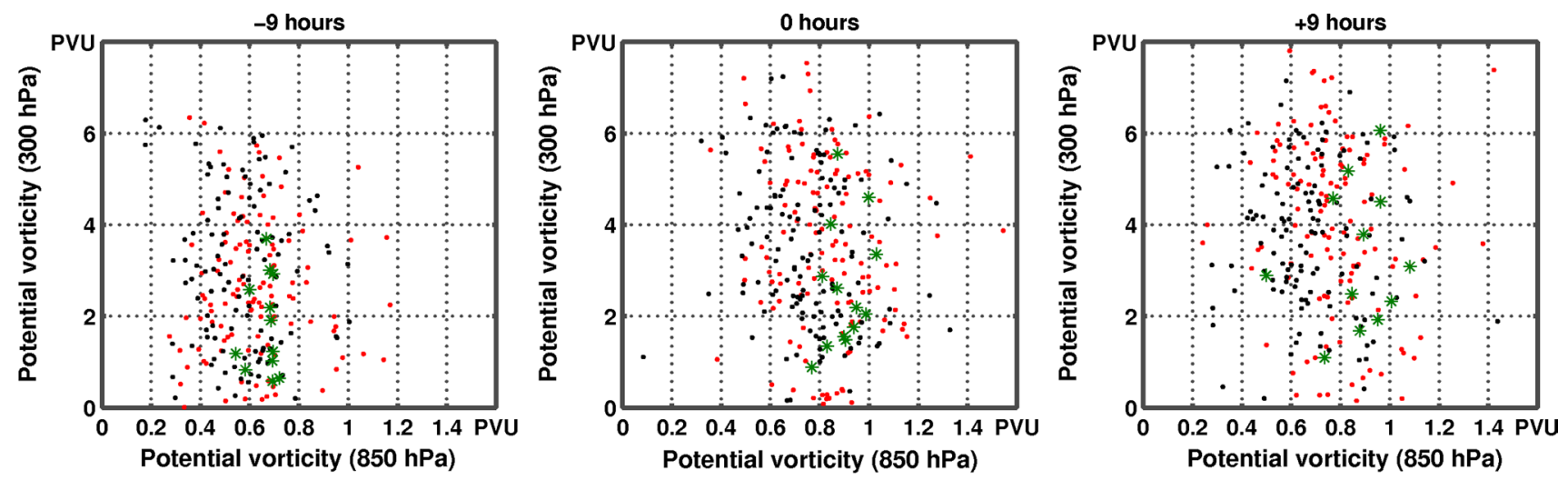

- Most intense cyclones - Weaker cyclones * Medicanes

Fig. 12 Scatterplot of PV at $850 \mathrm{hPa}$ versus $\mathrm{PV}$ at $300 \mathrm{hPa}$ at -9 , 0 and $+9 \mathrm{~h}$ for the 200 most intense cyclones (red dots), the 200 weaker cyclones (black dots) and the 13 Medicanes included in our dataset (green stars). Fields are averaged within a $200 \mathrm{~km}$ radius around the cyclone centers 
over the cyclone center. This contrast between upper-level and low-level PV suggests that for Medicanes the diabatic PV production at lower levels is particularly important. The latter should be anticipated since Medicanes are defined as systems of dense cloud coverage and hence systems of strong latent heating. However, searching in Fig. 12 all cyclones that present low-level PV values larger than 0.7 PVU at $-9 \mathrm{~h}$ and larger than $0.8 \mathrm{PVU}$ at 0 and $+9 \mathrm{~h}$, we find $\sim 30$ systems, i.e., about two times more cyclones than the 13 identified Medicanes. Therefore, the criterion of high, diabatically produced low-level PV is rather a necessary than a sufficient criterion for Medicanes.

\section{Summary and perspectives}

In this paper we analyzed the baroclinic life cycle of the most intense Mediterranean cyclones, as tracked in a high resolution coupled ocean-atmosphere regional simulation. The intense cyclones in the Mediterranean have been identified according to a relative vorticity threshold (which provided an ensemble of 200 cases), while our analysis revealed a common baroclinic life cycle for all cases. According to this cycle, a PV streamer, originating from the polar jet, intrudes the Mediterranean basin. The surface cyclone intensity increases while the streamer is located at the cyclone's western side and decreases when the streamer is wrapping over its center. As the cyclone intensifies, temperatures advection induced by the cyclonic PV streamer provokes a narrowing of the cyclone's warm sector. The cyclone structure has also been analyzed using air parcel trajectories. We showed that WCBs start within the warm sector of the cyclones, rise and turn anticyclonically in the upper troposphere. DAIs were identified that emerge from the exterior of the Mediterranean domain and end above the warm sector of the cyclones.

In a climatological perspective of the regional dynamics, our main result is that the dynamical structure of the Mediterranean cyclones presents a fairly common life cycle irrespective of their intensity. This life cycle is strongly determined by the protrusion of the PV streamer emerging from Rossby wave breaking, as already shown by previous studies. As discussed above, it is our hypothesis that the subtropical jet might play a crucial role on the baroclinic life cycle of Mediterranean cyclones by providing ambient barotropic shear, which favours the formation of cyclonically breaking PV streamers. Numerical sensitivity experiments will address this issue in a forthcoming paper in order to test our hypothesis.

Finally, we show in terms of processes of cyclone intensification, that Mediterranean cyclones cannot be regarded as a unique category, but they rather present baroclinc life cycle characteristics that are similar to other extratropical cyclones as the ones developing over the main storm track regions. Medicanes turned out to be cyclones that are similar to other intense cyclones, however typically with a particularly intense, diabatically produced, positive low-level PV anomaly and a PV streamer of slightly below-average intensity.

Acknowledgments EF was supported by the IMPACT2C program (funded by the European Union Seventh Framework Programme, FP7/2007-2013 under the grant agreement 282746) and the WRF simulation have been performed at the GENCI (IDRIS) under allocation i2012010227. SRR acknowledges funding from the ETH Postdoctoral Fellowship Program and the Marie Curie Actions for People COFUND program. The authors are thankful to Sebastian Schemm (ETH Zurich) for his remarks on the detection of conveyor belts. This work was also supported by the IPSL group for regional climate and environmental studies and also contributes to the HyMeX program (HYdrological cycle in The Mediterranean EXperiment) through INSU-MISTRALS support and the Med-CORDEX program (A Coordinated Regional climate Downscaling Experiment-Mediterranean region).

\section{References}

Appenzeller C, Davies HC (1992) Structure of stratospheric intrusions into the troposphere. Nature 358:570-572

Bleck R, Mattocks C (1984) A preliminary analysis of the role of potential vorticity in Alpine lee cyclogenesis. Beitr Phys Atmos $57: 357-368$

Browning KA (1990) Organization of clouds and precipitation in extra-tropical cyclones. In: Newton CW, Holopainen EO (eds) Extratropical cyclones: the Erik Palmen memorial volume. Am Meteorol Soc pp 129-153

Browning KA (1997) The dry intrusion perspective of extra-tropical cyclone development. Meteorol Appl 4:317-324. doi:10.1017/ S1350482797000613

Buzzi A, D'Isidoro M, Davolio S (2003) A case-study of an orographic cyclone south of the Alps during the MAP SOP. Q J R Meteorol Soc 129:1795-1818. doi:10.1256/qj.02.112

Čampa J, Wernli H (2012) A PV perspective on the vertical structure of mature midlatitude cyclones in the northern hemisphere. $\mathrm{J}$ Atmos Sci 69:725-740. doi:10.1175/JAS-D-11-050.1

Campins J, Genovés A, Jansà A, Guijarro JA, Ramis C (2000) A catalogue and a classification of surface cyclones for the western Mediterranean. Int J Climatol 20:969-984. doi:10.1002/10970088(200007)20:9<969:AID-JOC519>3.0.CO;2-4

Campins J, Jansà A, Genovés A (2006) Three-dimensional structure of western Mediterranean cyclones. Int J Climatol 26:323-343. doi:10.1002/joc. 1275

Campins J, Genovés A, Picornell MA, Jansà A (2011) Climatology of Mediterranean cyclones using the ERA-40 dataset. Int J Climatol 31:1596-1614. doi:10.1002/joc.2183

Catto JL, Shaffrey LC, Hodges KI (2010) Can climate models capture the structure of extratropical cyclones? J Clim 23:1621-1635. doi $: 10.1175 / 2009 J C L I 3318.1$

Chaboureau JP, Claud C (2006) Satellite-based climatology of Mediterranean cloud systems and their association with largescale circulation. J Geophys Res 111:D01102. doi:10.1029/200 5JD006460 
Chaboureau JP, Pantillon F, Lambert D, Richard E, Claud C (2012) Tropical transition of a Mediterranean storm by jet crossing. Q J R Meteorol Soc 138:596-611. doi:10.1002/qj.960

Chang EKM, Song S (2006) The seasonal cycles in the distribution of precipitation around cyclones in the western north Pacific and Atlantic. J Atmos Sci 63:815-839. doi:10.1175/JAS3661.1

Claud C, Alhammoud B, Funatsu BM, Chaboureau JP (2010) Mediterranean hurricanes: large-scale environment and convective and precipitating areas from satellite microwave observations. Nat Hazards Earth Syst Sci 10:2199-2213. doi:10.5194/nh ess-10-2199-2010

Davies HC, Schär C, Wernli H (1991) The palette of fronts and cyclones within a baroclinic wave development. J Atmos Sci 48:1666-1689

Davis CA, Emanuel KA (1991) Potential vorticity diagnostics of cyclogenesis. Mon Weather Rev 119:1929-1953. doi:10.1175/1520-0493(1991)119<1929:PVDOC >2.0.CO;2

Drobinski P et al (2012) Model of the regional coupled earth system (MORCE): application to process and climate studies in vulnerable regions. Environ Model Softw 35: 1-18. doi:10.1016/ j.envsoft.2012.01.017. ISSN 1364-8152

Drobinski P, Ducrocq V, Alpert P, Anagnostou E, Béranger K, Borga M, Braud I, Chanzy A, Davolio S, Delrieu G, Estournel C, Filali Boubrahmi N, Font J, Grubišić V, Gualdi S, Homar V, IvančanPicek B, Kottmeier C, Kotroni V, Lagouvardos K, Lionello P, Llasat MC, Ludwig W, Lutoff C, Mariotti A, Richard E, Romero R, Rotunno R, Roussot O, Ruin I, Somot S, Taupier-Letage I, Tintore J, Uijlenhoet R, Wernli H (2014) HyMeX: a 10-year multidisciplinary program on the mediterranean water cycle. Bull Am Meteorol Soc 95:1063-1082. doi:10.1175/BAMS-D-12-00242.1

Eckhardt S, Stohl A, Wernli H, James P, Forster C, Spichtinger N (2004) A 15-year climatology of warm conveyor belts. J Clim 17:218-237. doi:10.1175/1520-0442(2004)017<0218:AYCOWC>2.0.CO;2

Emanuel K (2005) Genesis and maintenance of "Mediterranean hurricanes". Adv Geosci 2:217-220

Field PR, Wood R (2007) Precipitation and cloud structure in midlatitude cyclones. J Clim 20:233-254

Field PR, Bodas-Salcedo A, Brooks ME (2011) Using model analysis and satellite data to assess cloud and precipitation in midlatitude cyclones. Q J R Meteorol Soc 137:1501-1515. doi:10.1002/qj. 858

Fita L, Romero R, Ramis C (2006) Intercomparison of intense cyclogenesis events over the Mediterranean basin based on baroclinic and diabatic influences. Adv Geosci 7:333-342. doi:10.5194/ad geo-7-333-2006

Fita L, Romero R, Luque A, Emanuel K, Ramis C (2007) Analysis of the environments of seven Mediterranean tropical-like storms using an axisymmetric, nonhydrostatic, cloud resolving model. Nat Hazards Earth Syst Sci 7:41-56. doi:10.5194/nh ess-7-41-2007

Flaounas E, Drobinski P, Bastin S (2013) Dynamical dowscaling of IPSL-CM5 CMIP5 historical simulations over the Mediterranean: benefits on the representation of regional surface winds and cyclogenesis. Clim Dyn 40:2497-2513. doi:10.1007/ s00382-012-1606-7

Flaounas E, Kotroni V, Lagouvardos K, Flaounas I (2014) CycloTRACK (v1.0) - tracking winter extratropical cyclones based on relative vorticity: sensitivity to data filtering and other relevant parameters. Geosci Model Dev 7:1841-1853. doi:10.5194/gmd-7-1841-2014

Giorgi F, Jones C, Asrar G (2009) Addressing climate information needs at the regional level: the CORDEX framework. WMO Bull 58(3):175-183

Hanley J, Caballero R (2012) The role of large-scale atmospheric flow and Rossby wave breaking in the evolution of extreme windstorms over Europe. Geophys Res Lett 39:L21708. doi:10.1029/ 2012GL053408
Holton JR (2004) An introduction to dynamic meteorology. Elsevier/ Academic Press. ISBN 0-12-354015-1

Homar V, Ramis C, Alonso S (2002) A deep cyclone of African origin over the Western Mediterranean: diagnosis and numerical simulation. Ann Geophys 20:93-106

Homar V, Jansà A, Campins J, Genovés A, Ramis C (2007) Towards a systematic climatology of sensitivities of Mediterranean high impact weather: a contribution based on intense cyclones. Nat Hazards Earth Syst Sci 7:445-454. doi:10.5194/n hess-7-445-2007

Horvath K, Fita L, Romero R, Ivančan-Picek B (2006) A numerical study of the first phase of a deep Mediterranean cyclone: cyclogenesis in the lee of the Atlas Mountains. Meteorol Z 15:133-146

Hoskins BJ, McIntyre ME, Robertson AW (1985) On the use and significance of isentropic potential vorticity maps. Q J R Meteorol Soc 111:877-946. doi:10.1002/qj.49711147002

Jansa A, Genoves A, Garcia-Moya JA (2000) Western Mediterranean cyclones and heavy rain. Part 1: numerical experiment concerning the Piedmont flood case. Meteorol Appl 7:323-333. doi:10.1017/ S1350482700001663

Kotroni V, Lagouvardos K, Defer E, Dietrich S, Porcù F, Medaglia CM, Demirtas M (2006) The Antalya 5 December 2002 storm: observations and model analysis. J Appl Meteorol Climatol 45:576-590. doi:10.1175/JAM2347.1

Kouroutzoglou J, Flocas HA, Keay K, Simmonds I, Hatzaki M (2011) Climatological aspects of explosive cyclones in the Mediterranean. Int J Climatol 31:1785-1802. doi:10.1002/joc.2203

Kysely J, Picek J (2007) Probability estimates of heavy precipitation events in a flood- prone central-European region with enhanced influence of Mediterranean cyclones. Adv Geosci 12:43-50

Lagouvardos K, Kotroni V, Defer E (2007) The 21-22 January 2004 explosive cyclogenesis over the Aegean Sea: observations and model analysis. Q J R Meteorol Soc 133:1519-1531. doi:10.1002/qj.121

Lebeaupin-Brossier C, Drobinski P, Béranger K, Bastin S, Orain F (2013) Ocean memory effect on the dynamics of coastal heavy precipitation preceded by a mistral event in the northwestern Mediterranean. Q J R Meteorol Soc 139:1583-1597. doi:10.1002/qj.2049

Madec G (2008) NEMO Ocean engine, note du pole de modélisation, Institut Pierre-Simon Laplace (IPSL), France (2008) No 27 ISSN No $1288-1619$

Madonna E, Wernli H, Joos H, Martius O (2014) Warm conveyor belts in the ERA-Interim data set (1979-2010). Part I: climatology and potential vorticity evolution. J Clim 27:3-26

McTaggart-Cowan R, Galarneau TJ, Bosart LF, Milbrandt JA (2010) Development and tropical transition of an Alpine lee cyclone. Part I: case analysis and evaluation of numerical guidance. Mon Weather Rev 138:2281-2307. doi:10.1175/2009MWR3147.1

Moody JL, Munger JW, Goldstein AH, Jacob DJ, Wofsy SC (1998) Harvard forest regional-scale air mass composition by patterns in atmospheric transport history (PATH). J Geophys Res 103:13181-13194

Moscatello A, Miglietta MM, Rotunno R (2008) Numerical analysis of a Mediterranean "hurricane" over south-eastern Italy. Mon Weather Rev 136:4373-4396

Neiman PJ, Shapiro MA (1993) The life cycle of an extratropical marine cyclone. Part I: frontal-cyclone evolution and thermodynamic air-sea interaction. Mon Weather Rev 121:2153-2176

Neu U et al (2013) IMILAST: a community effort to intercompare extratropical cyclone detection and tracking algorithms. Bull Am Meteorol Soc 94:529-547. doi:10.1175/BAMS-D-11-00154.1

Nieto R, Sprenger M, Wernli H, Trigo R, Gimeno L (2008) Identification and climatology of cutoffs lows near the tropopause. Ann N Y Acad Sci 1146:256-290. doi:10.1196/annals.1446.016 
Nissen KM, Leckebusch GC, Pinto JG, Renggli D, Ulbrich S, Ulbrich U (2010) Cyclones causing wind storms in the Mediterranean: characteristics, trends and links to large-scale patterns. Nat Hazards Earth Syst Sci 10:1379-1391. doi:10.5194/n hess-10-1379-2010

Omrani H, Drobinski P, Dubos T (2012) Investigation of indiscriminate nudging and predictability in a nested quasi-geostrophic model. Q J R Meteorol Soc 138:158-169

Omrani H, Drobinski P, Dubos T (2013) Optimal nudging strategies in regional climate modelling: investigation in a big-brother experiment over the European and Mediterranean regions. Clim Dyn 41:2451-2470

Pfahl S, Wernli H (2012) Quantifying the relevance of cyclones for precipitation extremes. J Clim 25:6770-6780. doi:10.1175/JCLI-D-11-00705.1

Pfahl S, Madonna E, Boettcher M, Joos H, Wernli H (2014) Warm conveyor belts in the ERA-Interim data set (1979-2010). Part II: moisture origin and relevance for precipitation. J Clim 27:27-40

Prezerakos NG, Flocas HA, Brikas D (2006) The role of the interaction between polar and subtropical jet in a case of depression rejuvenation over the Eastern Mediterranean. Meteorol Atmos Phys 92:139-151. doi:10.1007/s00703-005-0142-y

Pytharoulis I, Craig GC, Ballard SP (2000) The hurricane-like Mediterranean cyclone of January 1995. Meteorol Appl 7:261-279

Schär C, Sprenger M, Lüthi D, Jiang Q, Smith RB, Benoit R (2003) Structure and dynamics of an Alpine potential-vorticity banner. Q J R Meteorol Soc 129:825-855. doi:10.1256/qj.02.47

Schemm S, Wernli H (2014) The linkage between the warm and cold conveyor belts in an idealized extratropical cyclone. J Atmos Sci 71:1443-1459

Schemm S, Wernli H, Papritz L (2013) Warm conveyor belts in idealized moist baroclinic wave simulations. J Atmos Sci 70:627-652. doi:10.1175/JAS-D-12-0147.1

Shapiro MA, Wernli H, Bao JW, Methven J, Zou X, Doyle J, Holt T, Donall-Grell E, Nieman P (1999) A planetary-scale to mesoscale perspective of the life cycles of extratropical cyclones: the bridge between theory and observations. In: Shapiro MA, Gronas $\mathrm{S}$ (eds) The life cycles of extratropical cyclones. American Meteorological Society, Boston, MA, pp 139-185
Skamarock WC, Klemp JB (2008) A time-split nonhydrostatic atmospheric model for weather research and forecasting applications. J Comput Phys 227:3465-3485

Stoelinga MT (1996) A potential vorticity-based study of the role of diabatic heating and friction in a numerically simulated baroclinic cyclone. Mon Weather Rev 124:849-874

Tafferner A (1990) Lee cyclogenesis resulting from the combined outbreak of cold air and potential vorticity against the Alps. Meteorol Atmos Phys 43:31-47

Thorncroft CD, Hoskins BJ, McIntyre ME (1993) Two paradigms of baroclinic-wave life-cycle behaviour. Q J R Meteorol Soc 119:17-55. doi:10.1002/qj.49711950903

Tosi E, Smith RB, Bradford ML (1987) Aerial observations of stratospheric descent in a Gulf of Genoa cyclone. Meteorol Atmos Phys 36(1987):141-160

Tous M, Romero R (2013) Meteorological environments associated with medicane development. Int $\mathrm{J}$ Climatol 33:1-14. doi:10.1002/joc. 3428

Trigo IF, Bigg GR, Davies TD (2002) Climatology of cyclogenesis mechanisms in the Mediterranean. Mon Weather Rev 130:549 569. doi:10.1175/1520-0493(2002)130<0549:COCMIT>2.0. $\mathrm{CO} ; 2$

Ulbrich U, Leckebusch GC, Pinto JG (2009) Extratropical cyclones in the present and future climate: a review. Theor Appl Climatol 96:117-131

Wernli H, Davies HC (1997) A Lagrangian-based analysis of extratropical cyclones. I: the method and some applications. Q J R Meteorol Soc 123:467-489

Wernli H, Dirren S, Liniger MA, Zillig M (2002) Dynamical aspects of the life cycle of the winter storm 'Lothar' (24-26 December 1999). Q J R Meteorol Soc 128:405-429. doi: $10.1256 / 003590002321042036$

Ziv B, Saaroni H, Romem M, Heifetz E, Harnik N, Baharad A (2010) Analysis of conveyor belts in winter Mediterranean cyclones. Theor Appl Climatol 99:441-455. doi:10.1007/ s00704-009-0150-9 